\title{
PANORAMA E POTENCIALIDADES PARA PUBLICAÇÃO DE ARTIGOS CIENTÍFICOS NA ÁREA AMBIENTAL
}

\author{
PAPER PUBLISHING OVERVIEW AND POTENTIALITIES IN \\ THE ENVIRONMENTAL ACADEMIC AREA
}

Recebido em: 17/09/2012 Aprovado em: 25/10/2012 Avaliado pelo sistema double blind review Editora Científica: Manolita Correia Lima

\author{
DENIZE DEMARCHE MINATTI FERREIRA dminatti@terra.com.br \\ CAROLINA AGUIAR DA ROSA \\ JOSÉ ALONSO BORBA \\ UNIVERSIDADE FEDERAL DE SANTA CATARINA
}

\section{RESUMO}

As questões relativas ao meio ambiente fizeram emergir preocupações socioambientais em todos os segmentos e, em especial, no empresarial, o que influenciou o aumento de pesquisas em determinadas áreas. No campo das Ciências Sociais Aplicadas não foi diferente; a demanda relativa a preocupações ligadas ao meio natural influenciou o aumento das pesquisas, cujas questões ligadas ao tema têm sido destaque. Este artigo teve por objetivo realizar um levantamento dos periódicos de língua inglesa e portuguesa, disponíveis no Portal de Periódicos da CAPES, que apresentassem nos títulos termos relevantes e relacionados à questão ambiental. Quanto à natureza, essa pesquisa caracteriza-se como descritiva e quanto aos procedimentos pode ser dita documental. Na escolha dos periódicos tomou-se como base a existência dos termos "environmental", "sustainability" e "green" para os periódicos internacionais e, os relacionados a "ambiente/meio ambiente", "sustentabilidade/sustentável" e "verde" em periódicos nacionais. Foram encontrados 40 periódicos disponíveis no Portal. Como resultado, constatou-se a existência de espaço para pesquisas na área de Ciências Sociais Aplicadas e sua relação com o meio ambiente no Brasil, visto que somente um periódico relacionado aos termos examinados está disponível.

Palavras-chave: meio ambiente; periódicos; ciências sociais aplicadas; portal CAPES.

\section{ABSTRACT}

Issues regarding the environment gave rise to socio-environmental concerns in all segments, especially in business, which also influenced the increase in research for certain areas. This also applies to Applied Social Sciences, where the demand regarding concerns related to the natural environment has influenced the increase in research, with an emphasis on issues connected to the subject. This paper aims at carrying out a survey of the English and Portuguese periodicals available on CAPES' Portal that contain titles with search terms relating to environmental issues. This research is characterized as descriptive and its procedures can be said to be documentary. The choice of journals was made based on the presence of the terms "environmental", "sustainability" and "green" for international journals, and related terms in the national ones. 40 periodicals were found to match the criteria in the Portal. As a result of a bibliometric analysis, it was concluded that there is a vast scope for research in Applied Social Science and its relationship with the environment in Brazil, since only one journal related to the terms searched is available for consultation.

Keywords: environment; journals; applied social sciences; CAPES portal. 


\section{INTRODUÇÃO}

A comunicação é elemento indispensável para a atividade científica, uma vez que, sem ela, não existiria ciência e não se poderiam somar os esforços individuais dos membros das comunidades científicas (OliveIra, 2002). Já a comunicação científica, para o mesmo autor, é aquela que pode ser entendida como o conjunto de atividades associadas à disseminação e ao uso da informação e, é importante para a aceitação do que é produzido cientificamente como constituinte do conhecimento científico. Ou seja, a produção de informações científicas e sua comunicação fazem parte de um sistema complexo, cujo funcionamento é essencial ao desenvolvimento do conhecimento científico (REY, 1978).

É de praxe avaliar os pesquisadores quanto à sua contribuição para a ciência por meio da análise de sua produção de artigos em periódicos que são vistos como um dos principais meios de divulgação. Assim, a comunicação científica se efetiva, normalmente, em teses, dissertações, relatórios, anais de eventos e em periódicos, entre outros.

A publicação de artigos em periódicos representa uma parte relevante do fluxo de informação originado da pesquisa científica (OLIVEIRA, 2002). Além disso, a publicação em periódicos especializados constitui um esforço importante na carreira dos pesquisadores, pois permite uma exteriorização de sua produção, sendo também a forma pela qual o pesquisador comunica aos seus pares seus achados (FREZATTI; BORBA, 2000).

Conforme Beuren (2003), o artigo de periódico é um trabalho técnico ou científico que visa principalmente maior agilidade na divulgação do assunto tratado, seguindo as normas de publicação do periódico a que se destina.

No caso deste trabalho, cabe destacar também a ponderação de Oliveira (2002, p. 69), que especifica a importância da produção em periódicos, como aquela em que: (I) os artigos podem ser colecionados, classificados, catalogados e reproduzidos infinitamente; (II) os cientistas não publicam livros nem defendem teses e dissertações com frequência, a agilidade na circulação destes veículos e, consequentemente, da informação contida neles, principalmente quando se trata de teses e dissertações, é mais lenta e; (III) 
os artigos de periódicos atingem mais velozmente que teses e dissertações um público maior, servem como fonte de bibliografia e contribuem para a atualização dos que os leem.

Outro aspecto relevante que deve ser avaliado e diz respeito a publicações em periódicos é a área de conhecimento em que são publicados os trabalhos. Diversas áreas têm se mobilizado em prol do desenvolvimento de ações que minimizem ou reduzam a interferência danosa do homem no meio ambiente, já que a sociedade convive com o fato de que os recursos naturais são escassos e que a ação do homem interfere significativamente no equilíbrio natural e impacta na qualidade de vida. Assim, a gestão ambiental e a busca pela sustentabilidade tornaram-se elementos de atenção por parte dos gestores e pesquisadores, mesmo que muitas vezes motivados por interesses diversos ou obrigados por força legal ou social (SILVA et al., 20II).

Diversos trabalhos na temática ambiental ligados às Ciências Socias Aplicadas têm demonstrado o crescente interesse pela área. No campo da administração e de operações internacionais, Machado Júnior, Souza e Ribeiro (20I2) verificaram as características da produção científica dos artigos sobre sustentabilidade ambiental no SIMPOI, no período de 1998 a 20II. Os resultados mostraram uma estabilidade no número de artigos aprovados no evento anualmente, com um crescimento significativo na participação de pesquisas na área de sustentabilidade ambiental. Na área contábil, Oliveira (2002), por meio do levantamento de características de artigos publicados em cinco periódicos nacionais da área do período de I990 a 1999, percebeu que temas atuais e importantes, como Contabilidade Social e Ambiental, ainda carecem de pesquisas. $\mathrm{O}$ autor destaca que o foco das publicações na área segue a linha da contabilidade tradicional, quase sempre, sem priorizar as questões relativas à preservação ambiental. Diferentemente de outros países emergentes, a pesquisa de Nascimento et al. (2009) demonstrou que não foram encontrados trabalhos da área ambiental de pesquisadores brasileiros em periódicos internacionais. Os autores destacam que, ao mesmo tempo em que pode ser um problema a ser compreendido, é também uma oportunidade de refletir sobre a inserção da pesquisa brasileira no cenário internacional. 
Até nas Instituições de Ensino Superior - IEs, essa preocupação crescente em busca de um desenvolvimento sustentável vem surgindo. Tauchen e Brandli (2006) investigaram a questão de práticas de gestão ambiental em IES brasileiras e comentam que os casos de gestão em âmbito universitário encontrados não só no Brasil, mas como no mundo, constituem, na maioria das vezes, práticas isoladas já implementadas e que já estão em funcionamento, demonstrando uma preocupação não só no aspecto do ensino, mas de práticas de funcionamento ambientalmente corretas.

Quanto ao idioma em que são publicados os periódicos, atualmente, quase a totalidade dos mesmos com fator de impacto só aceitam manuscritos escritos em inglês. A importância da língua inglesa na comuinação científica internacional é indiscutível. Portanto, as publicações científicas nessa língua, para qualquer país, têm maior aceitação junto à comunidade científica mundial. Em relação às revistas brasileiras, é possível que as que publicam em inglês gozem de melhor conceito tanto no meio interno como externo. As agências de fomento preferem periódicos que imprimem nesse idioma (MONTEIRO, 1984).

Percebe-se ainda pouca repercussão nos meios empresariais e discretos avanços nos meios acadêmicos em relação à disseminação da própria discussão sobre o tema, haja vista a importância da questão ambiental e a necessidade de introduzir esta variável nas práticas de gestão e nas estratégias das organizações (sennem et al., 20I2). Desta forma, é importante que os pesquisadores conheçam as oportunidades de publicação em periódicos ligados à área de meio ambiente, principalmente no âmbito internacional, já que foi identificada uma carência de pesquisas, que especifiquem os perfis dos periódicos da área de ambiental. É neste sentido que este trabalho pretende contribuir. Deste modo, o presente artigo teve por objetivo realizar um levantamento dos periódicos da área ambiental e de sustentabilidade em língua inglesa e portuguesa, com o intuito de apresentar um panorama bem como compreender as possíveis potencialidades para publicação na área de Ciências Sociais Aplicadas. 
REFERENCIAL TEÓRICO

\section{MEIO AMBIENTE}

Existem incontáveis definições para os termos meio ambiente e sustentabilidade. Barbieri (2007), por exemplo, define meio ambiente como um conjunto de forças e condições que cercam e influenciam os seres vivos. Conforme a Resolução n ${ }^{\circ} 307$ do conAma de 05/07/2002, meio ambiente pode ser definido, também, como o conjunto de condições, leis, influências e interações de ordem física, química, biológica, social, cultural e urbanística, que permite, abriga e rege a vida em suas formas.

Para Santos (1994; 2006, p. 5), ao se falar em meio ambiente, é preciso entender, antes de mais nada, a formação desse "meio técnico" que hoje é passível de ser apreendido na relação do "lugar" com o mundo, posto que a técnica é a base de realização da mundialidade como totalidade empírica e esta só é alcançada por meio dos lugares, na medida em que os lugares exprimem a funcionalização do mundo. $\mathrm{O}$ mesmo autor adverte que quando se fala em meio ambiente, certos enfoques atuais podem aparecer como reducionistas, na medida em que eles apenas se interessam por um dos aspectos de uma complexa problemática. Por exemplo, uma visão puramente ideológica da questão, uma visão puramente econômica ou uma preocupação exclusivamente tópica (sANTOS, 2006).

Merico (I996) diz que é preciso perceber o conjunto de valores que direcionam o desenvolvimento econômico e, consequentemente, a relação com o ambiente natural que encontrou uma barreira instransponível: os limites da biosfera. A mudança paradigmática, que é enfrentada, apresentase como elemento reorganizador dos processos econômicos, cujo principal eixo é a busca da sustentabilidade. Portanto, o sentido de orientação do desenvolvimento econômico deverá ser a inserção dos processos econômicos nos limites da biosfera, o que coloca a operacionalização da sustentabilidade como um grande desafio para as civilizações futuras.

O que se nota é que a degradação ambiental é resultado direto das formas pelas quais o homem se apropria e usufrui da natureza. É primordial, 
portanto, que se estabeleça a compreensão de que os modelos de consumo e de produtividade exercem intensa influência nos meios naturais, sendo fundamental entender tanto os conceitos como a relação entre meio ambiente e sustentabilidade.

Para Cavalcanti (1998), sustentabilidade quer dizer o reconhecimento de limites biofísicos colocados, incontornavelmente, pela biosfera no processo econômico. Essa é uma percepção que sublinha o fato de que a ecologia sustenta a economia, dessa forma, obrigando-a a operar em sintonia com os princípios da natureza. Para o mesmo autor, o discurso oficial, entretanto, gira em torno da ideia de que o desenvolvimento sustentável pode ser conquistado com o crescimento infinito, desde que certas ressalvas de proteção ambiental sejam observadas. É uma noção que difere da compreensão de que meio ambiente deve ser visto como a fonte derradeira de certas funções, sem as quais a economia simplesmente não pode existir ou operar, e cujos ritmos determinam a velocidade do que pode ser feito. Para ser sustentável, com efeito, o sistema econômico deve possuir uma base estável de apoio, o que requer que capacidades e taxas de regeneração e absorção sejam respeitadas, caso contrário, o processo econômico torna-se irremediavelmente insustentável (CAVALCANTI, 1998).

Para Leff (20I0), o debate pela sustentabilidade é uma batalha conceitual. O autor diz que não se trata de ver o porquê de alguns conceitos se mostrarem mais "sedutores" ou "politicamente corretos", tornando-se mais apropriáveis em imaginários, em subjetividades e em formações discursivas, como: "dívida ecológica”, "justiça ambiental” ou o próprio "desenvolvimento sustentável”. Não se trata de ver como os conceitos vão se sedimentando, legalizando e legitimando em processos históricos por meio de estratégias de poder no saber. Para o autor, o interessante é descobrir como os conceitos vão sendo incorporados nos imaginários sociais e nos discursos de atores diferenciados.

A definição mais popular de desenvolvimento sustentável é aquela que diz que se deve atender às necessidades da geração atual sem comprometer o direito de as futuras gerações atenderem às suas próprias necessidades 
(relatório Brundtland, WCED, 1987). Desenvolvimento sustentável, segundo Martínez Allier (1998), também remete ao conceito de capacidade de sustentação, próprio da ciência ecológica; todavia, aqueles que o introduziram (IUCN - International Union for the Conservation of Nature e Comissão Brundtland das Nações Unidas) com grande êxito, queriam combinar conscientemente as ideias de desenvolvimento econômico e capacidade de sustento.

Portanto, a função ambiental deixa de ser exclusiva da produção para tornar-se uma função administrativa. Interfere no planejamento estratégico, no desenvolvimento das atividades de rotina, na discussão dos cenários alternativos e, consequentemente, na análise de sua evolução, gerando políticas, metas e planos de ação de qualquer organização (MAIMON, 1996). Para tanto, deve-se considerar que os limites da natureza são fatores restritivos, que a produtividade em limites máximos e em curto prazo é incompatível com os princípios da sustentabilidade, além do que é eminente a dificuldade de identificar e quantificar os impactos ambientais.

\section{ESTUDOS RELACIONADOS}

A preocupação com as questões ambientais tem suscitado interesse não só nas áreas específicas, mas nas diversas áreas de conhecimento, fazendo crescer o número de pesquisadores e, consequentemente, o número de artigos em eventos e periódicos científicos. Desde a década de 1970, aumentou o número de pesquisas direcionadas à questão socioambiental e aos problemas a ela relacionados (MANSINHO; SCHIMIDT, I994).

$\mathrm{Na}$ área das ciências sociais, a dimensão da dinâmica ambiental também começou a ganhar importância nos objetivos da sua produção ou das suas preocupações científicas. O ambiente deixou de ser encarado como uma simples limitação imposta às sociedades humanas e ganhou o estatuto de uma problemática, na qual se inscreve a própria transformação dessas sociedades (MANSINHO; SCHIMIDT, I994). Os fatos motivaram as autoras a identificar em vários campos das ciências sociais trabalhos que de algum modo convergissem, ou levassem em conta, a temática ambiental; por 
outro lado, consideraram também trabalhos ligados a várias outras áreas disciplinares, que podem ser vistos como inputs indispensáveis a estudos (em ciências sociais) que venham a desenvolver-se sobre o ambiente.

Segundo Lorenzetti e Delizoicov (2005), há evidente crescimento da pesquisa na área ambiental. Os autores classificaram todos os programas de pós-graduação que tinham trabalhos produzidos em educação ambiental, de acordo com as áreas do conhecimento adotadas pelo CNPq. Analisaram 366 trabalhos sobre educação ambiental desenvolvidos nos programas de pós-graduação em Educação e em Ensino, onde, foram encontradas 343 dissertações e 23 teses. Na década de 1980, foram produzidos I, $9 \%$ dos trabalhos, na de $90,40,2 \%$ e no período de 2000 a $2003,57,9 \%$ dos trabalhos localizados. Para Lorenzetti e Delizoicov (2005), é evidente que a temática ambiental tem sido objeto de estudo nos programas de pós-graduação em todas as áreas de conhecimento. Os autores destacam que, na área de conhecimento das Ciências Sociais Aplicadas, foram encontradas 45 dissertações e 5 teses, que representam 6,1\% dos trabalhos de todas as áreas.

Kanashiro (20I0) investigou, por meio de análise de conteúdo, como a temática ambiental tem sido abordada e apropriada por acadêmicos brasileiros nos artigos da base Scielo Brasil. No que se refere à distribuição dos artigos por área do conhecimento, tomou-se como critério a classificação estabelecida pela própria base Scielo (ciências agrárias, ciências biológicas, ciências exatas e da terra, ciências da saúde, ciências humanas, ciências sociais aplicadas, engenharias). $\mathrm{O}$ autor afirma que existe uma produção crescente de artigos sobre o tema no Brasil, feita por cientistas de diversas áreas do saber, existindo maior heterogeneidade nas revistas de ciências humanas e sociais aplicadas e certa predominância das concepções da ecoeficiência e do ecodesenvolvimento na amostra de artigos analisada.

Jabbour, Santos e Barbieri (2008) realizaram uma meta-análise da produção científica em gestão ambiental empresarial de seis dos principais periódicos em administração no Brasil (RAE, RAEE, RAUSP, RAP, REAd e RAC), no período entre 1996 e 2005. Os autores examinaram a produção acadêmica baseada nos seguintes parâmetros: aumento da produção; origem de autoria; perfil metodológico; conteúdo e abrangência das análises; e nível 
de internacionalização das referências bibliográficas. Foram 4I trabalhos publicados entre os 1.785 registrados nos seis periódicos analisados. Isso significa que a produção científica dessa área de pesquisa corresponde a apenas $2,30 \%$ do total da área de administração. Assim, a despeito da área de gestão ambiental empresarial ser uma das mais concorridas no âmbito dos eventos acadêmicos em administração, ela ainda encontra pouca expressividade nos periódicos de grande prestígio. Os autores destacam que o quadro só não se mostrou mais crítico pelo lançamento de uma edição especial da ReAd sobre o tema.

Sehnem et al. (2012) identificaram a evolução do interesse de publicação nas questões da gestão, estratégia e desempenho ambientais em português, inglês e espanhol em periódicos AI, A2, Bı e B2 da área de Administração, Ciências Contábeis e Turismo. Foram pesquisadas I.203 edições disponibilizadas eletronicamente, entre 2000 e 2009, com a identificação de II3 artigos, de 22 periódicos. Os autores observaram que, no período analisado, houve crescimento de periódicos brasileiros e número de artigos publicados, inclusive com edições especiais sobre a questão ambiental, porém, com difusão pouco significativa nas publicações brasileiras, haja vista que somente foi identificado um artigo para cada ro edições analisadas.

Novais, João e Serralvo (2012) perquisaram e identificaram a literatura acadêmica corrente sobre sustentabilidade, na temática de gestão e pesquisa em negócios, usando análise bibliométrica, a fim de obter uma visão geral sobre um campo de conhecimento, bem como investigar quais tópicos estão associados a este assunto e que são considerados como mais relevantes. A análise dos dados envolveu abordagens qualitativas e quantitativas. Em termos de pesquisa qualitativa, foram tratados aspectos relacionados ao conteúdo, palavras-chave e relevância. Em relação aos aspectos quantitativos, as variáveis adotadas foram: número total de publicações, autores, áreas temáticas, fontes documentais, títulos, ano de publicação, instituições, idiomas e países. Os autores buscaram a descrição de revistas e seu fator de impacto, verificando o Journal Citation Report (JCR) da base ISI (Web of Science). Os 3.009 artigos selecionados abordam o tema "sustentabilidade" sob a perspectiva da economia, administração e gestão, apontando para 
o desenvolvimento econômico e o estímulo às ações de responsabilidade social. Moretti e Campanario (2009) caracterizaram em seu trabalho o estado da arte das publicações brasileiras, na área da responsabilidade social empresarial, ao delinearem o perfil dos autores, sua produção e citações bibliográficas por eles utilizadas no EnANPAD, entre 1997 e 2007. Corroborando, Gallon et al. (2008) traçaram um panorama da produção científica em administração sobre a temática ambiental e identificaram categorias das pesquisas científicas e mapearam as fontes de referências utilizadas nos artigos. Os autores ressaltam que, apesar de recorte feito em relação à área do estudo, o elevado número de publicações no período de 2000 a 2006 evidencia sua consolidação. Ainda, um aspecto positivo comentado pelos autores é o fato de se identificar alguma perspectiva de inserção internacional; porém, constatou-se, ainda, o uso muito forte de livros, produção consolidada, mas que não reflete necessariamente o estado da arte da temática, pelo menos no sentido de processo contínuo de construção de conhecimento. 


\section{PROCEDIMENTOS METODOLÓGICOS}

Esta pesquisa pode ser classificada como descritiva quanto aos objetivos por propor-se a descrever o perfil dos periódicos científicos na área das Ciências Sociais Aplicadas. Para Gil (2002, p. 42), "as pesquisas descritivas têm como objetivo primordial a descrição das características de determinada população ou fenômeno ou, então, o estabelecimento de relações entre variáveis”.

Quanto aos procedimentos, pode ser dita pesquisa documental, que consiste na coleta, classificação, seleção difusa e na utilização de toda espécie de informações na forma de textos, imagens e outros (FACHIN, 200I).

A amostra da pesquisa foi obtida por uma seleção de periódicos. Foi realizado um levantamento, acessando-se o Portal de Periódicos da CAPES, que foi criado para oferecer informação científica à comunidade acadêmica brasileira. O acesso é permitido a professores, pesquisadores, funcionários e alunos de graduação e pós-graduação das instituições participantes.

A busca no Portal se deu por periódicos da área de conhecimento de "Ciências Sociais Aplicadas", que apresentassem nos títulos termos de pesquisa relevantes e relacionados à questão ambiental, ou seja, que contivessem determinadas palavras no mesmo. Tendo em vista os objetivos do presente artigo, foram selecionados para análise somente os periódicos em que os títulos apresentassem os termos; "environmental", "sustainability" e "green" para os periódicos internacionais e, os relacionados em periódicos nacionais; "ambiente/meio ambiente", "sustentabilidade/sustentável" e "verde". O levantamento contemplou 38 revistas, 37 de língua inglesa e I de língua portuguesa, sendo que destas 4 já cessaram suas edições.

Avaliou-se dentre outras características: a presença de ISSN (International Standard Serial Number), a idade, a periodicidade, o Fator de Impacto (FI), o escopo e algumas observações relevantes destacadas em relação à publicação analisada. 


\section{RESULTADOS}

Num primeiro momento, a pesquisa concentrou-se em listar e estudar periódicos científicos disponíveis no Portal capes, bem como as características que asseguram qualidade e disseminação dos artigos que nos mesmos são publicados.

Foram encontrados 37 periódicos em língua inglesa, sendo que 4 já cessaram, e apenas I em língua portuguesa, totalizando 34 ainda ativos. Diferentemente do Brasil, organismos oficiais têm um relacionamento direto com pesquisas na área social e ambiental, sendo que estes estudos subsidiam políticas públicas, alteração da legislação dos países e desempenho institucional das empresas (NASCIMENTo et al., 2009). Tal fato pode justificar a reduzida quantidade de periódicos brasileiros encontrados.

Novais, João e Serralvo (20I2), por meio de uma análise bibliométrica, reforçaram a predominância da produção acadêmica em inglês, linguagem, mais usual no campo dos negócios, apesar de os autores mais prolíficos, Asheim e Grainer, não serem de países de língua inglesa. Há algumas publicações muito discretas em outros idiomas, tais como: tcheco, português, eslovaco, dinamarquês e russo.

O tempo de circulação (longevidade) constitui um dos aspectos relacionados com a consolidação de um periódico (RUMMLER; SILVA, 2005). Poucas revistas, que representam i3\% do total pesquisado, possuem uma longevidade maior que 20 anos, como pode ser visto na Tabela I. Conforme o tempo de circulação, grande parte das revistas (34\%) pode ser considerada "recente", tendo no máximo io anos.

Tabela 1 Longevidade dos periódicos

\begin{tabular}{|ll|}
\hline Longevidade & Quantidade \\
\hline 1 a 5 anos & $9^{*}$ \\
\hline 6 a 10 anos & $4^{* *}$ \\
\hline 11 a 15 anos & 15 \\
\hline 16 a 20 anos & 5 \\
\hline 21 a 25 anos & 2 \\
\hline
\end{tabular}




\begin{tabular}{|ll|}
\hline Longevidade & Quantidade \\
\hline 26 a 30 anos & 0 \\
\hline 31 a 35 anos & 2 \\
\hline 36 a 40 anos & 1 \\
\hline Total & $\mathbf{3 8}$ \\
\hline
\end{tabular}

^ Destas revistas, 1 iniciou em 2000 e cessou em 2002; linicou em 1999 e cessou em 2001; 1 iniciou em 2000 e cessou em 2001.

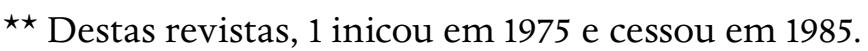

Segundo Rummler e Silva (2005), os primeiros 5 anos de uma revista podem ser considerados como período probatório para sua sobrevivência, o que pode ser corroborado pelos achados desta pesquisa, que, entre as 9 revistas com longevidade de até 5 anos, 3 delas cessaram, em média, em 2 anos.

As preocupações com as questões socioambientais nas organizaçoes têm influenciado o aumento e a sistematização de pesquisas em diversas áreas de conhecimento. Esse cenário proporcionou subsídios, fazendo com que estudos realizados proporcionassem avanços do conhecimento já existente.

Desde a década de 1970, emergiram preocupações com o meio ambiente, fazendo também crescer os estudos nessa área. Calixto (2004) afirma que "a questão ambiental surgiu na literatura contábil com maior intensidade a partir da década de 1970", entretanto, em alguns países se encontra em fase de desenvolvimento como é o caso do Brasil (CUNHA; PORTE; NAHUZ JÚNIOR, 2OII).

Gráfico 1 Ano de criação dos periódicos

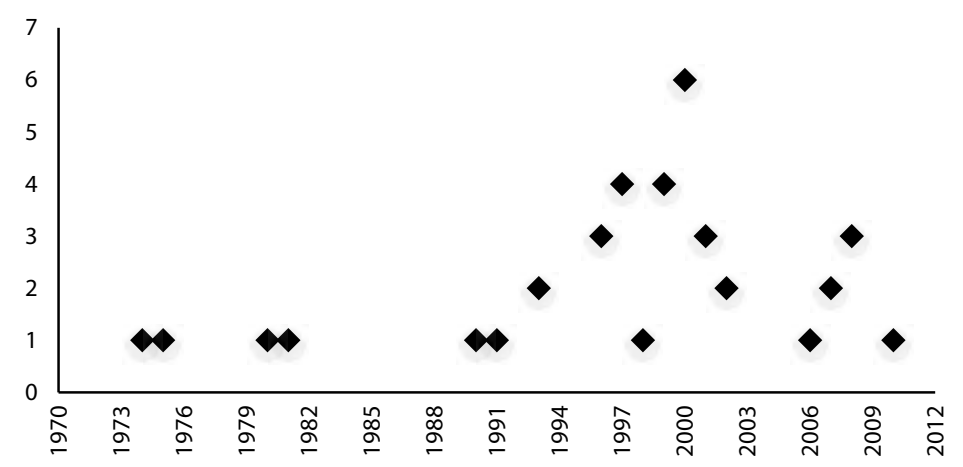


Entre os periódicos de maior impacto (estratos AI, A2, Bi e B2) da área de Administração, Souza et al. (20II) relatam que o ápice de publicações sobre o tema sustentabilidade ambiental se deu nos anos de 2005 e 2006. Os autores comentam que as edições especiais sobre o tema, que justificam esse crescimento, coincidem com acontecimentos internacionais de grande impacto, como a ratificação do Protocolo de Kyoto, em agosto de 2005.

O Gráfico I mostra o surgimento dos periódicos nos anos de 1970, destacando-se uma proliferação de periódicos a partir da década de 1990, com destaque para o ano 2000. Tais resultados vão de encontro ao estudo de Souza et al. (20II), que demonstra um aumento substancial de artigos publicados sobre sustentabilidade ambiental a partir de 2002, e apresenta uma evolução percentual aproximada de $154 \%$ para 2006. O número de artigos teve um crescimento razoável de 2008 para 2009, mantendo-se praticamente estável em 2010.

A Tabela 2 apresenta algumas características das revistas, entre elas seus editores, sua periodicidade, o IsSN, fator de impacto e a área na qual se enquadram.

A periodicidade é uma informação relevante para quem pretende enviar artigos para publicação. Quanto mais frequente for o periódico, maior agilidade na circulação da informação. Observar a regularidade da revista também pode ser fundamental para a publicação de artigos, atestando-se desse modo a confiabilidade do periódico, no que diz respeito à circulação das informações (OLIVEIRA, 2002).

Destaca-se que entre os periódicos pesquisados, I3 têm edições trimestrais, 9 deles são bimestrais e 5 são semestrais. Observou-se que uma das revistas possui periodicidade irregular, o que não é aconselhável, tendo-se em vista que uma das características básicas da publicação periódica está vinculada à definição e à regularidade.

Um indicador relacionado às citações de sites que vem gerando um grande interesse entre os estudiosos que atuam no campo da webometria é o fator de impacto da Web (Web Impact Factor - WIF). Ingwersen (1998) sugeriu a criação de uma medição análoga àquela do fator de impacto de revistas - calculado pelo isI (Institut for Scientific Information) nas suas bases 
de dados de citações - que permitisse a comparação do grau de atratividade de sites ou domínios na Web (VANTI, 2002).

Vanti (2002) comenta que o fator de impacto na web implica a soma do número de links contidos em páginas externas e internas, que se referem a um determinado país ou site dividido pelo número de páginas encontradas nesse país ou site, em certo momento. Comenta também que, em comparação com as citações científicas de revistas, instituições ou indivíduos, as quais podem ser estáveis ou aumentar o número de links que remetem a um objeto particular pode diminuir ou até desaparecer. Isto ocorre devido ao eventual fechamento ou à reestruturação de certas páginas, que estavam disponíveis em algum momento na rede e que mudaram ou que não estão mais, o que impossibilita, nestes casos, um cálculo retrospectivo do fator de impacto.

A busca para verificar o fator de impacto das revistas pesquisadas foi realizada nas bases Web of Science (wos) (do ISI Web of Knowledge) e Scopus. Com o uso crescente pela busca do fator de impacto, o ISI passou a publicar anualmente o JCR (Journal Citation Reports) que é um recurso que permite avaliar e comparar publicações científicas utilizando dados de citações extraídos de revistas acadêmicas e técnicas e o impacto destas na comunidade científica. Verifica os periódicos mais citados em uma determinada área e a relevância da publicação para a comunidade científica por meio do fator de impacto. O sJR (SCImago Journal \& Country Rank) é um portal (<http://www.scimagojr.com $>$ ), que inclui revistas científicas e indicadores desenvolvidos com base no banco de dados Scopus, (http:// www.scopus.com/home.url), desde 1996, que são utilizados para avaliar e analisar os domínios científicos, mostrando assim a visibilidade de tais revistas. É necessário destacar que são utilizados critérios de cálculos diferentes e a possibilidade de determinado periódico estar presente em uma das bases ou nas duas. Na Tabela 2, além dos respectivos fatores de impacto na Web of Sience e/ou na Scopus, é apresentado também o número de publicações dos periódicos, indexadas nas bases de dados pesquisadas.

De acordo com a análise da quantidade de vezes que o país apareceu na base de dados dos periódicos em língua inglesa da área de contabilidade do 
estudo de Nascimento et al. (2009), os países com destaque são: Reino Unido, em função da tradição de pesquisa na área ambiental e manutenção dos principais centros de estudos; Austrália, pois organismos governamentais demandam pesquisas da área; e Estados Unidos, baseados no aumento da preocupação com governança. Os resultados encontrados corroboram em parte com a pesquisa realizada, pois $38 \%$ dos periódicos são de origem dos EUA e $24 \%$ da Inglaterra. Os achados de Nascimento et al. (2009) dão enfoque ao Reino Unido (35\%), Austrália (18\%) e EUA (16\%). Tais achados podem ser questionáveis. É interessante também que se conheça a vinculação do periódico a uma univesidade e/ou a sua disponibilização por uma empresa (Elsevier, Gale Cengage Academic OneFile, Wiley Online Library, Springer, entre outras), o que certamente também influencia nas estatísticas das publicações. 
PANORAMA E POTENCIALIDADES PARA PUBLICAÇÃO DE ARTIGOS CIENTÍFICOS NA ÁREA AMBIENTAL

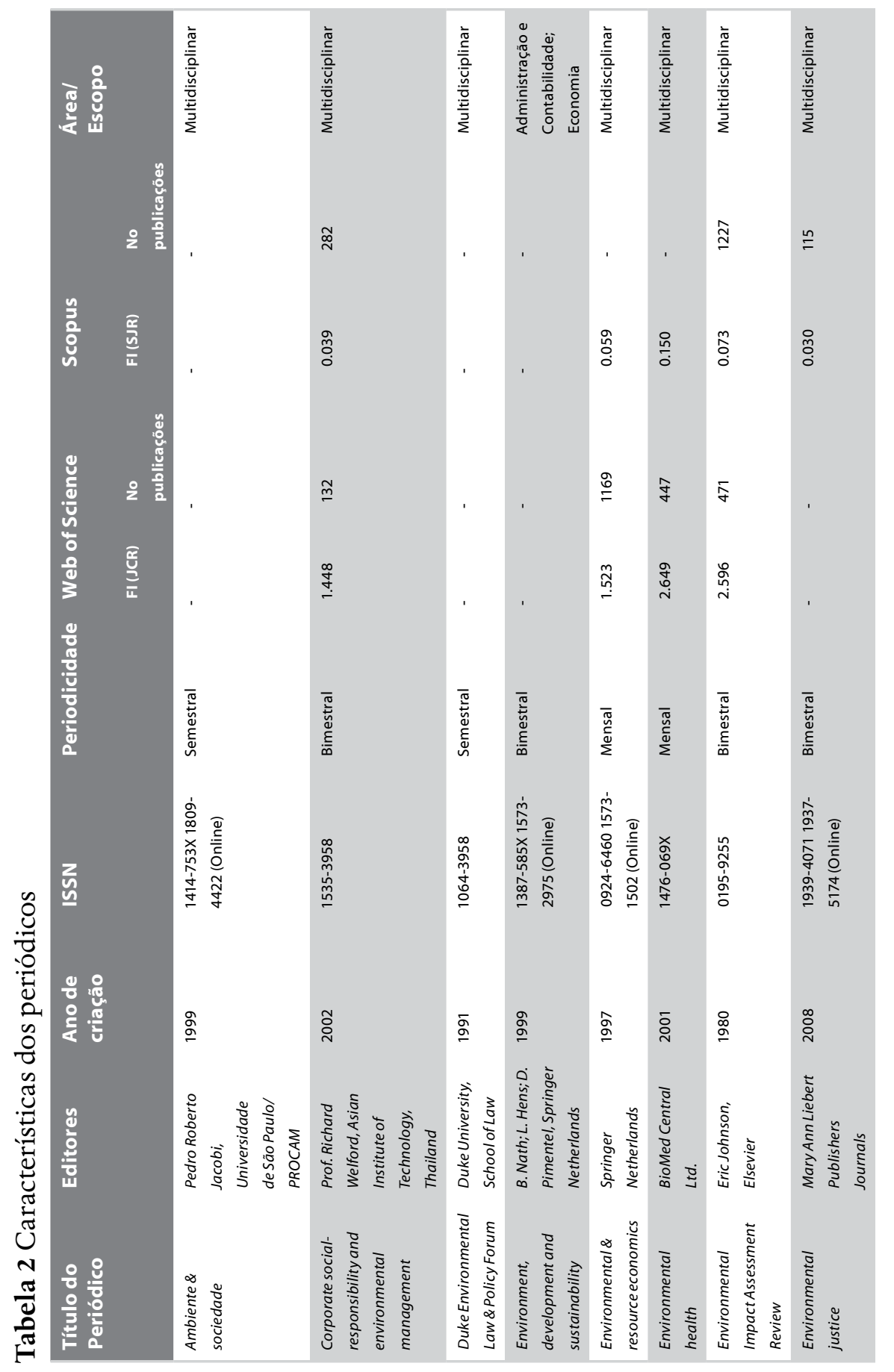




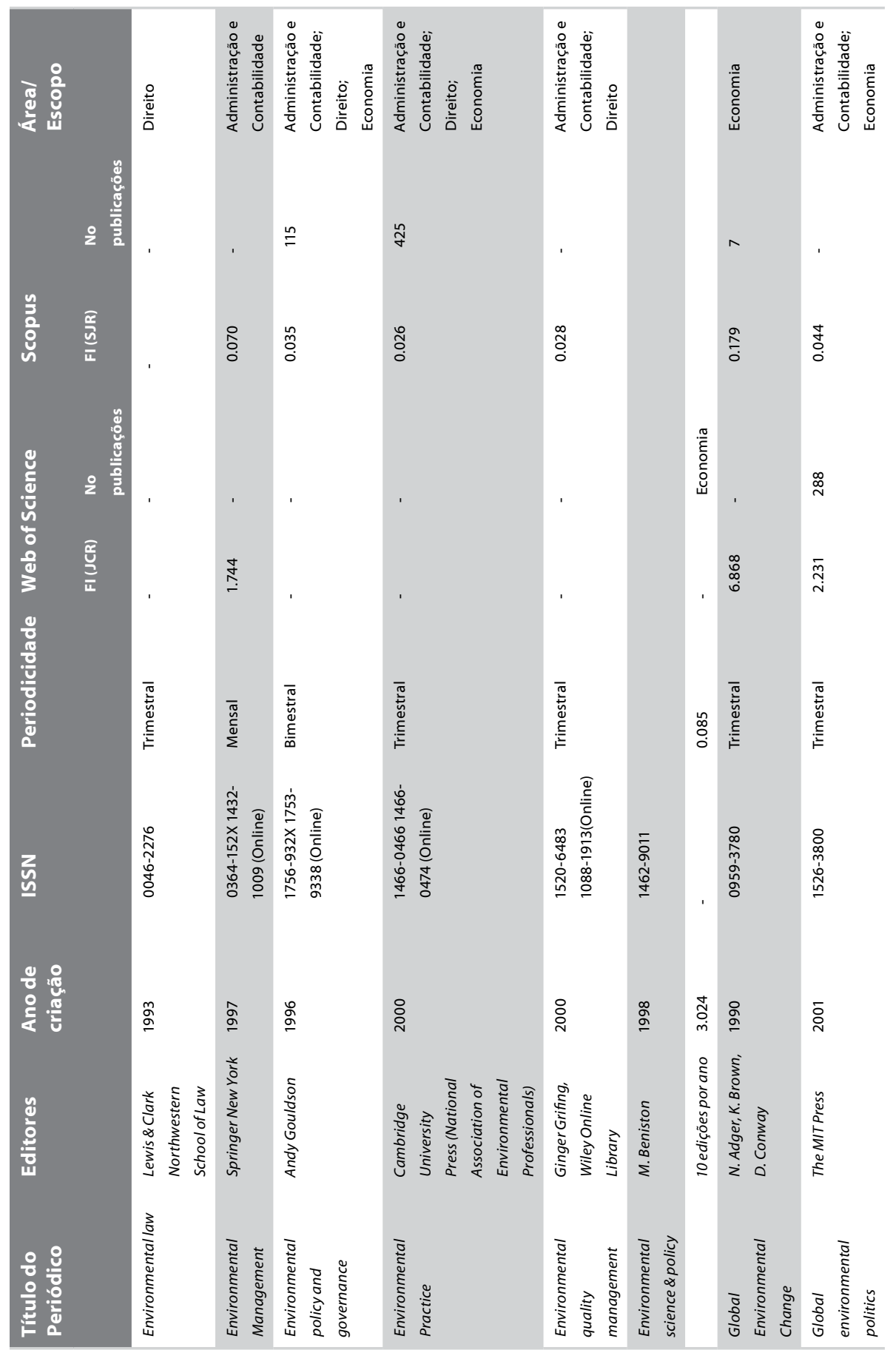


PANORAMA E POTENCIALIDADES PARA PUBLICAÇÃO DE ARTIGOS CIENTÍFICOS NA ÁREA AMBIENTAL

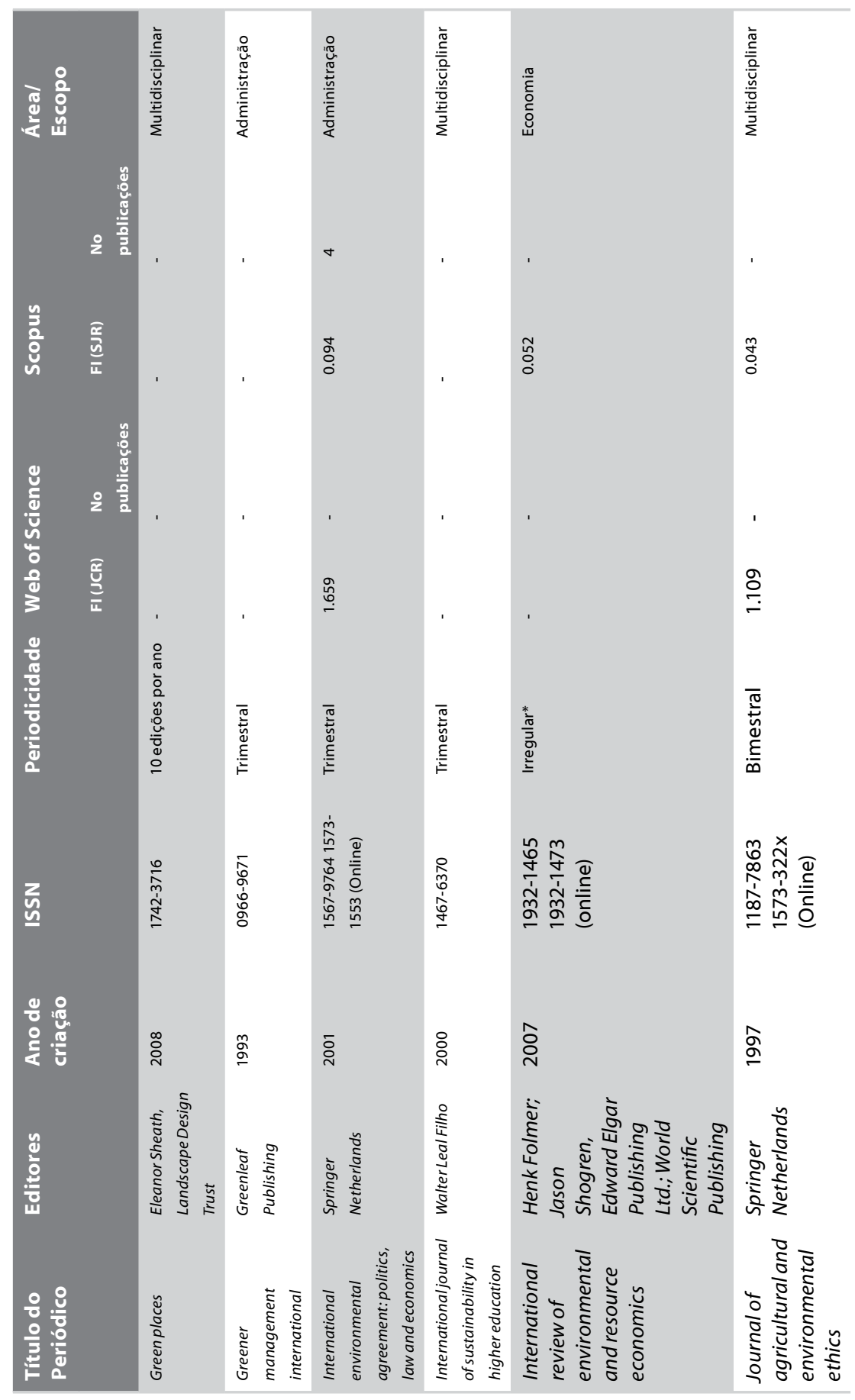




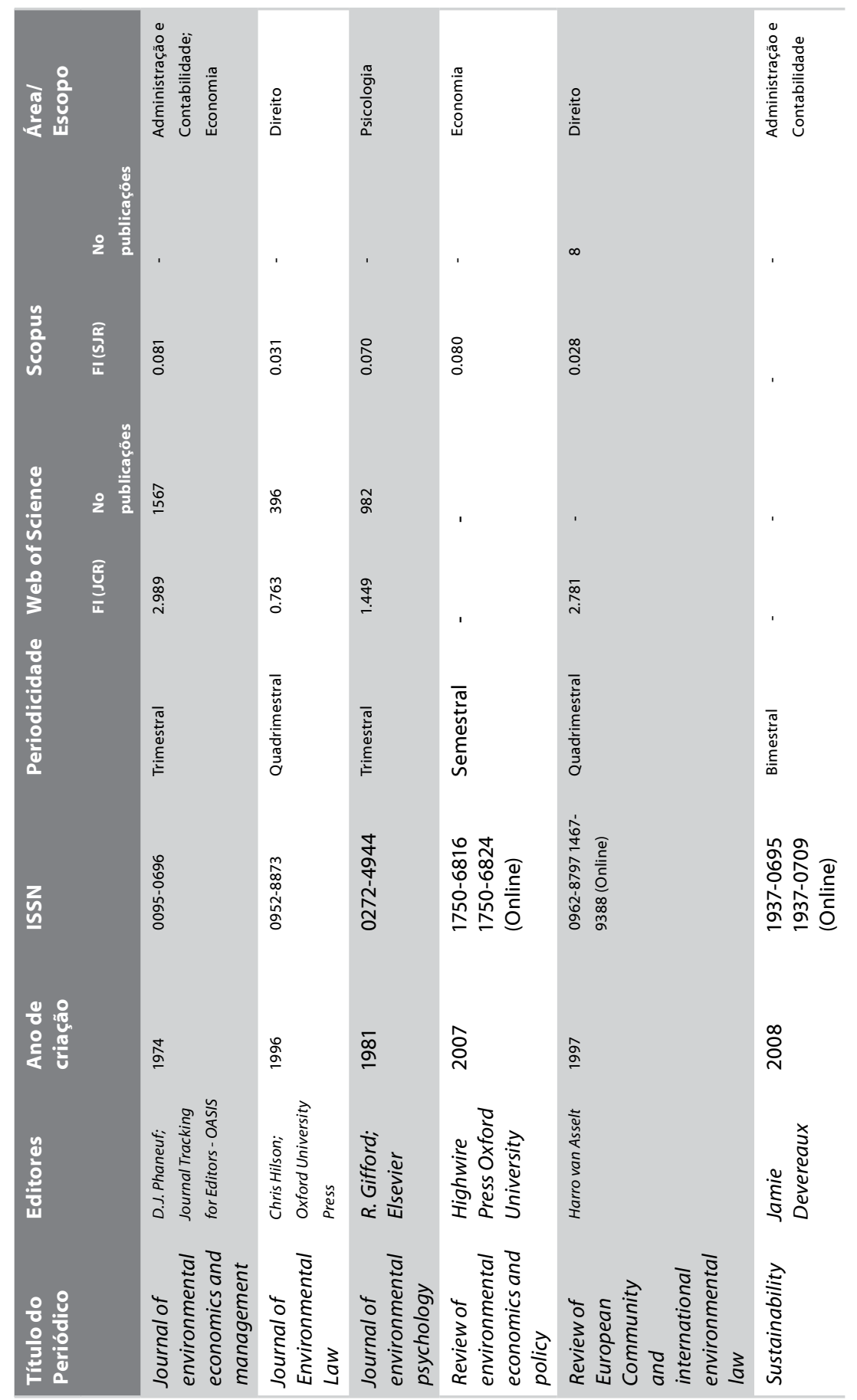


PANORAMA E POTENCIALIDADES PARA PUBLICAÇÃO DE ARTIGOS CIENTÍFICOS NA ÁREA AMBIENTAL

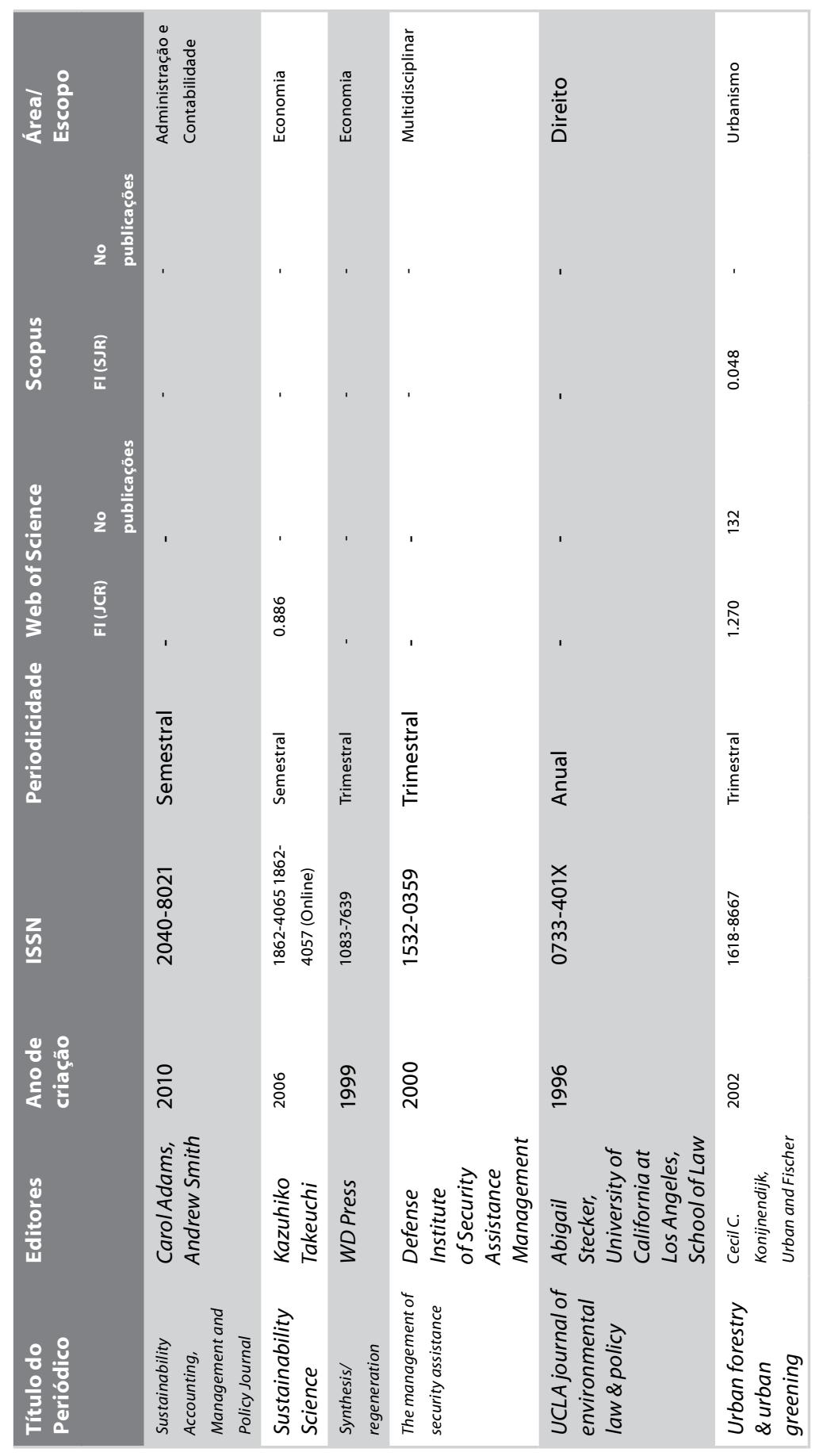


Com o intuito de conhecer os periódicos e as temáticas de interesse, nos Quadros I, 2 e 3 são apresentadas as revistas voltadas à área de contabilidade e administração, economia e direito e à descrição de seus respectivos escopos.

No Quadro I são evidenciadas in (32\%) revistas que abordam, predominantemente, questões relacionadas à área de administração e contabilidade, com temas entre negócios, administração, governança e contabilidade e meio ambiente. É importante destacar que esses periódicos não são exclusivamente da área, podendo haver a divulgação de artigos que não sejam desta temática.

Quadro 1 Periódicos relacionados à área de administração e contabilidade

\begin{tabular}{|c|c|}
\hline $\begin{array}{l}\text { Environment, development and } \\
\text { sustainability }\end{array}$ & $\begin{array}{l}\text { Impactos ambientais do desenvolvimento } \\
\text { socioeconômico, interações entre desenvolvimento e } \\
\text { meio ambiente. }\end{array}$ \\
\hline Environmental Management & $\begin{array}{l}\text { Gestão ambiental, ecologia, conservação da natureza, quali- } \\
\text { dade atmosférica, controle e poluição do ar, gestão de florestas, } \\
\text { gestão de resíduos, poluição e gestão das águas. }\end{array}$ \\
\hline $\begin{array}{l}\text { Environmental policy and } \\
\text { governance }\end{array}$ & $\begin{array}{l}\text { Relações internacionais, política, direito, economia, sociologia, } \\
\text { administração, geografia, estudos de desenvolvimento da } \\
\text { ciência e tecnologia. Ciências ambientais em debates contem- } \\
\text { porâneos sobre a política e governança. Contribuições políti- } \\
\text { cas relevantes no campo da economia ecológica. }\end{array}$ \\
\hline Environmental Practice & $\begin{array}{l}\text { Ciência e tecnologia associadas às questões de política pública, } \\
\text { saúde, qualidade ambiental, direito, política, economia, admi- } \\
\text { nistração e normas para perícia. }\end{array}$ \\
\hline $\begin{array}{l}\text { Environmental quality } \\
\text { management }\end{array}$ & $\begin{array}{l}\text { Desempenho ambiental, normas voluntárias (ISO } 14000 \text { e certi- } \\
\text { ficação), gestão da qualidade ambiental, práticas de medição de } \\
\text { desempenho, avaliação do ciclo de vida (ACV), gestão da segu- } \\
\text { rança, auditoria ambiental, normas, contabilidade ambiental, } \\
\text { comunicação ambiental, desenvolvimento sustentável, bench- } \\
\text { marking ambiental, direito ambiental global. }\end{array}$ \\
\hline Global environmental politics & $\begin{array}{l}\text { Políticas globais e gestão de mudanças ambientais, com aten- } \\
\text { ção para as implicações locais, globais e política mundial, ciên- } \\
\text { cias políticas, relações internacionais, sociologia, história, geo- } \\
\text { grafia humana, política pública, ciência e estudos de tecnologia, } \\
\text { ética ambiental, economia e ciências ambientais. }\end{array}$ \\
\hline $\begin{array}{l}\text { Greener management } \\
\text { international }\end{array}$ & $\begin{array}{l}\text { Negócios, indústrias, ciência e teconologia ambiental, ques- } \\
\text { tões ambientais e como afetam o mundo. }\end{array}$ \\
\hline
\end{tabular}




\begin{tabular}{|c|c|}
\hline $\begin{array}{l}\text { Environment, development and } \\
\text { sustainability }\end{array}$ & $\begin{array}{l}\text { Impactos ambientais do desenvolvimento } \\
\text { socioeconômico, interações entre desenvolvimento e } \\
\text { meio ambiente. }\end{array}$ \\
\hline $\begin{array}{l}\text { International environmental } \\
\text { agreements: politics, law and } \\
\text { economics }\end{array}$ & $\begin{array}{l}\text { Questões ambientais e recursos naturais, incluindo (biossegu- } \\
\text { rança, perda de biodiversidade, alterações climáticas, deser- } \\
\text { tificação, conservação de florestas, destruição da camada de } \\
\text { ozônio, fluxo de poluentes transfronteiriços, gestão dos recur- } \\
\text { sos marinhos e de água doce), o papel da sociedade civil na } \\
\text { definição e na resolução de conflitos ambientais. }\end{array}$ \\
\hline $\begin{array}{l}\text { Journal of environmental } \\
\text { economics and management }\end{array}$ & $\begin{array}{l}\text { Relações entre os sistemas econômicos e ambientais e recursos } \\
\text { naturais. Gestão de questões políticas e sua relação com o meio } \\
\text { ambiente natural. }\end{array}$ \\
\hline Sustainability & $\begin{array}{l}\text { Mudanças climáticas, conservação de recursos, modificação de } \\
\text { comportamento trazendo diversidade no campo da sustentabi- } \\
\text { lidade; fusão/cortes no orçamento, ambiente construído, boas } \\
\text { práticas de ensino superior, entidades sem fins lucrativos e } \\
\text { setor privado, agricultura sustentável. }\end{array}$ \\
\hline $\begin{array}{l}\text { Sustainability Accounting, } \\
\text { Management and Policy Journal }\end{array}$ & $\begin{array}{l}\text { Contabilidade de carbono, Negociação e Governança Cor- } \\
\text { porativa e responsabilidade social, impacto econômico das } \\
\text { políticas de sustentabilidade socioambiental, contabilidade } \\
\text { da gestão ambiental, ética ambiental, direitos humanos, estra- } \\
\text { tégias de sustentabilidade, políticas socioambientais, estudos } \\
\text { organizacionais, auditorias e relatórios, desenvolvimento } \\
\text { sustentável, bem-estar no local de trabalho. }\end{array}$ \\
\hline
\end{tabular}

Murcia et al. (2008) citam que, diferentemente do cenário nacional, o tema disclosure ambiental é bastante pesquisado no âmbito internacional, e traz como exemplo o periódico australiano Accounting, Auditing and Accountability Journal, que realizou duas edições especiais sobre os temas Social and Environmental Reporting, em 2002, e Ethical, Social and Environmental Accounting, em 2007.

Dessa forma, é importante mencionar que os resultados desta pesquisa não esgotam a análise dos periódicos da área ambiental, vinculados à área das Ciências Sociais Aplicadas. Cabe destacar que este estudo se limita a periódicos que possuem em seus títulos termos relacionados à sustentabilidade e meio ambiente. Estudos relacionados à disclosure ambiental e social demonstram que os periódicos de contabilidade com maior número de publicações são: Accounting, Auditing and Accountability Journal; Critical Perspective on Accounting; Accounting, Organizations and Society e The British Accounting Review (NASCImento et al., 2009). Nenhuma 
dessas revistas possui em seus títulos termos da área ambiental, porém a pluralidade temática dos mesmos e a caracterização como principais periódicos de contabilidade do mundo geram interesse em publicações na área ambiental.

\section{Quadro 2 Periódicos voltados à área de economia}

\begin{tabular}{|c|c|}
\hline $\begin{array}{l}\text { Environment, development } \\
\text { and sustainability }\end{array}$ & $\begin{array}{l}\text { Impactos ambientais do desenvolvimento socioeconômico, } \\
\text { interações entre desenvolvimento e meio ambiente. }\end{array}$ \\
\hline $\begin{array}{l}\text { Environmental policy and } \\
\text { governance }\end{array}$ & $\begin{array}{l}\text { Relações internacionais, política, direito, economia, sociologia, } \\
\text { administração, geografia, estudos de desenvolvimento da ciência } \\
\text { e tecnologia. Ciências ambientais em debates contemporâneos } \\
\text { sobre a política e governança. Contribuições políticas relevantes } \\
\text { no campo da economia ecológica. }\end{array}$ \\
\hline $\begin{array}{l}\text { International review of } \\
\text { environmental and resource } \\
\text { economics }\end{array}$ & Recursos ambientais e suas ligações com a economia. \\
\hline Environmental Practice & $\begin{array}{l}\text { Ciência e tecnologia associadas às questões de política pública, } \\
\text { saúde, qualidade ambiental, direito, política, economia, adminis- } \\
\text { tração e normas para perícia. }\end{array}$ \\
\hline Environmental science \& policy & $\begin{array}{l}\text { Questões ambientais (alterações climáticas, biodiversidade, } \\
\text { poluição ambiental, resíduos, recursos renováveis e não reno- } \\
\text { váveis, sustentabilidade) e interações entre as mesmas. Relações } \\
\text { entre questões ambientais, sociais e econômicas (produção, } \\
\text { transporte, consumo, crescimento, mudanças demográficas, } \\
\text { bem-estar e saúde). }\end{array}$ \\
\hline Global Environmental Change & $\begin{array}{l}\text { Dimensões humanas e políticas das mudanças ambientais glo- } \\
\text { bais, biodiversidade e serviços ambientais, recursos hídricos, } \\
\text { mudanças climáticas, políticas públicas, economia, patrimônio, } \\
\text { risco e resiliência, política científica, saúde e bem-estar. }\end{array}$ \\
\hline Global environmental politics & $\begin{array}{l}\text { Políticas globais e mudanças ambientais, com atenção para as } \\
\text { implicações locais, globais e política mundial, ciências políticas, } \\
\text { relações internacionais, sociologia, história, geografia humana, } \\
\text { política pública, ciência e estudos de tecnologia, ética ambiental, } \\
\text { economia e ciências ambientais. }\end{array}$ \\
\hline $\begin{array}{l}\text { Journal of environmental } \\
\text { economics and management }\end{array}$ & $\begin{array}{l}\text { Relações entre os sistemas econômicos e ambientais e recursos } \\
\text { naturais. Questões políticas e sua relação com o meio ambiente } \\
\text { natural. }\end{array}$ \\
\hline $\begin{array}{l}\text { Review of environmental } \\
\text { economics and policy }\end{array}$ & Economia ambiental e políticas relacionadas. \\
\hline Sustainability Science & $\begin{array}{l}\text { Mudanças climáticas, economia ambiental, ecologia da paisa- } \\
\text { gem, saúde pública. }\end{array}$ \\
\hline $\begin{array}{l}\text { Synthesis/Regeneration } \\
\text { A Magazine of Green Social } \\
\text { Thought }\end{array}$ & $\begin{array}{l}\text { Política regional, ciência política, questões políticas e ambien- } \\
\text { tais. }\end{array}$ \\
\hline
\end{tabular}


Destaca-se, também, a área de economia voltada a questões ambientais. O Quadro 2 apresenta II periódicos da área encontrados na pesquisa. Entre estes, três possuem um enfoque bem específico da temática, limitando-se nos seus escopos questões da economia ambiental. Por outro lado, outras revistas são mais amplas, abordando também questões de administração e direito, periódicos esses que também aparecem nos Quadros i e 3.

Quadro 3 Periódicos voltados à área de direito

\begin{tabular}{|c|c|}
\hline environmental law & $\begin{array}{l}\text { Especialidades legais, leis locais e internacionais, } \\
\text { leis ambientais. }\end{array}$ \\
\hline $\begin{array}{l}\text { environmental policy and } \\
\text { governance }\end{array}$ & $\begin{array}{l}\text { Relações internacionais, política, direito, economia, sociolo- } \\
\text { gia, administração, geografia, estudos de desenvolvimento da } \\
\text { ciência e tecnologia. Ciências ambientais em debates contem- } \\
\text { porâneos sobre a política e governança. Contribuições políticas } \\
\text { relevantes no campo da economia ecológica. }\end{array}$ \\
\hline environmental practice & $\begin{array}{l}\text { Ciência e tecnologia associadas às questões de política pública, } \\
\text { saúde, qualidade ambiental, direito, política, economia, admi- } \\
\text { nistração e normas para perícia. }\end{array}$ \\
\hline journal of environmental law & Direito ambiental. \\
\hline $\begin{array}{l}\text { review of european community } \\
\text { and international environmental } \\
\text { law }\end{array}$ & $\begin{array}{l}\text { Direito ambiental europeu e internacional, incluindo, mas não } \\
\text { limitado à mudança climática, comércio internacional e meio } \\
\text { ambiente, direito internacional da água, responsabilidade } \\
\text { ambiental, gestão de resíduos e proteção da biodiversidade. }\end{array}$ \\
\hline $\begin{array}{l}\text { ucla journal of environmental law } \\
\& \text { policy }\end{array}$ & $\begin{array}{l}\text { Direito ambiental e internacional, especialidades jurídicas, } \\
\text { cobertura e análise nos diferentes campos da lei. }\end{array}$ \\
\hline
\end{tabular}

No Quadro 3 são evidenciados periódicos da área de direito. Esses periódicos representam $18 \%$ do total da amostra pesquisada, que, em sua maioria, possuem um enfoque predominante em direito ambiental e referentes às leis que envolvem a temática. 


\section{Quadro 4 Periódicos Multidisciplinares ou voltados a outras temáticas}

\section{Ambiente e Sociedade \\ Articula a interface entre 0 ambiente e Ciências Sociais,}

Corporate social responsibility and environmental

management

\begin{tabular}{|ll|}
\hline $\begin{array}{l}\text { Duke Environmental Law \& } \\
\text { Policy Forum }\end{array}$ & $\begin{array}{l}\text { Estudos de caso com vistas a melhorar o desempenho e a pres- } \\
\text { tação de contas na área de desenvolvimento sustentável. }\end{array}$ \\
$\begin{array}{ll}\text { Environmental \& resource } \\
\text { economics }\end{array}$ & $\begin{array}{l}\text { Avaliação e desenvolvimento de instrumentos de política } \\
\text { ambiental, custo-benefício e custo-eficácia, análise de impacto } \\
\text { setorial da política ambiental, modelagem e simulação, arranjos } \\
\text { institucionais, avaliação dos bens ambientais, indicadores de } \\
\text { qualidade ambiental. }\end{array}$ \\
\hline
\end{tabular}

Environmental health

Pesquisa, estudos de casos em inovação na área da saúde ambiental, ciência ambiental e aspectos relacionados à saúde humana.

Environmental Impact

Assessment Review

Environmental justice

\begin{tabular}{l} 
Green places \\
$\begin{array}{l}\text { International journal of } \\
\text { sustainability in higher } \\
\text { education }\end{array}$ \\
\hline
\end{tabular}

Journal of agricultural and environmental ethics com abordagem interdisciplinar.

Responsabilidade socioambiental no contexto do desenvolvimento sustentável.

Teoria e práticas inovadoras em estudos de impacto ambiental - EIA.

Saúde para o ambiente, ciência tecnologia e meio ambiente, uso da terra e planejamento urbano, políticas públicas, história ambiental, história jurídica no que se refere à justiça ambiental, sociologia e antropologia das disparidades de saúde ambiental e iniciativas populares.

Criação, gestão e utilização de espaços públicos.

Sistemas de gestão ambiental, desenvolvimento sustentável, Agenda 21, aspectos operacionais das instituições de ensino superior, políticas ambientais, desenvolvimento e aplicação de indicadores de sustentabilidade.

Agricultura, produção de alimentos e preocupações ambientais, questões éticas relativas às responsabilidades dos produtores agrícolas, avaliação das mudanças tecnológicas que afetam as populações rurais, utilização de terras agrícolas, agricultura intensiva, modificação dos ecossistemas, bem-estar animal, biotecnologia, disponibilidade e acessibilidade aos alimentos.

The management of security assistance

Sistemas de defesa, relações internacionais, ciência militar e naval; ciência política, ciência e tecnologia, indústrias de fabricação.

Journal of environmental psychology

Inter-relações entre as pessoas e seu entorno físico (incluindo ambientes construídos e naturais, o uso da natureza e sustentabilidade relacionada com comportamento), reflexões acerca do desenvolvimento científico e da psicologia ambiental.

Urban forestry \& urban greening
Florestas urbanas, ecologia urbana, políticas, planejamento e projetos, gestão de florestas. 
Por fim, estão relacionados no Quadro 4 os periódicos que apresentam em seus escopos uma abrangência maior de temas, considerados multidisciplinares para fins desta pesquisa, ou seja, não se direcionam a um tema específico, como somente áreas de administração, contabilidade, economia e direito, que foram destacados nos quadros anteriores. Ainda, se encontram periódicos de outras áreas, como é o caso do Journal of environmental psychology, voltado à psicologia e o Urban forestry \& urban greening, da área de ecologia urbana. 


\section{CONSIDERAÇÕES FINAIS}

A questão da sustentabilidade ambiental passou a ocupar lugar preponderante no debate acadêmico e político, principalmente a partir do final da década de 1960. Os grandes eventos internacionais impactaram direta ou indiretamente a impulsão de pesquisas sobre sustentabilidade no âmbito internacional e nacional, que tiveram uma forte influência na disseminação do tema em periódicos científicos de diversas áreas do conhecimento (souza et al., 20II).

Os autores destacam que no Brasil, as primeiras publicações sobre sustentabilidade na área de administração são da década de 1990 e contribuíram para disseminar o tema. A partir do início desse século, o tema encontra-se consolidado nos principais congressos e periódicos da área, fomentando estudos sobre a produção científica em sustentabilidade.

Murcia e Borba (2008) dizem que no âmbito nacional, especificamente na área da contabilidade, o conhecimento científico tem se disseminado de maneira lenta, com poucas publicações em periódicos de alto nível. Os autores afirmam existir um considerável consenso acadêmico em relação ao fato de que a pesquisa poderia ter um impacto significativo na solução dos problemas das organizações, uma vez que, no Brasil, como uma das principais economias do mundo, a pesquisa contábil brasileira deveria acompanhar esse desenvolvimento.

Este artigo procurou contribuir para um melhor entendimento do estágio atual do perfil dos periódicos, especificamente da área das ciências sociais aplicadas. Os resultados deste estudo mostram que a produção de periódicos que contemplam a produção da referida área, no Brasil, é extremamente baixa, visto que somente um periódico nacional, que contivesse as palavras da busca no título, foi encontrado.

A pesquisa listou e avaliou os periódicos científicos disponíveis no Portal CAPES, bem como as características que asseguram qualidade e disseminação dos artigos que são publicados No mesmo portal.

Foram encontrados 37 periódicos em língua inglesa, dos quais 4 já cessaram, e apenas I em língua portuguesa, totalizando 34 ainda ativos. Para a consecução dos objetivos propostos, investigou-se a longevidade 
e o surgimento dos periódicos, cabendo destacar aqui um incremento no número de revistas depois da década de 1970, quando emergiram as preocupações ambientais. Por julgar importante a informação para os pesquisadores que pretendem publicar seus artigos, destacam-se ainda, o fator de impacto, a vinculação e um detalhamento das áreas temáticas de interesse.

Os dizeres de Souza et al. (20II) corroboram o que foi encontrado nesta busca, ao afirmarem que a área é recente e que ainda não atingiu maturidade nas publicações, mas que está a caminho da consolidação, pois o número de artigos demonstra tendência de crescimento e há algumas características que favorecem a qualidade da pesquisa em sustentabilidade: a pluralidade de áreas de interesse; o crescimento de estudos feitos por grupos de pesquisadores ao invés de iniciativas individuais; a distribuição que tende a ser uniforme entre artigos quantitativos e qualitativos nos últimos anos do estudo, demonstrando uma cobertura metodológica complementar, que pode trazer maior qualidade às pesquisas.

Por fim, sugere-se a futuros trabalhos a investigação mais aprofundada do panorama dos periódicos, com a inclusão de novos termos de busca. Além disso, estudos que contemplem os temas ambientais mais abordados nesses periódicos podem contribuir para a disseminação da temática. 


\section{REFERENNCIAS}

BARBIERI, J. C. Gestão ambiental empresarial: conceitos, modelos e instrumentos. 2.ed. atual. e ampl. São Paulo: Saraiva 2007.

BEUREN, I. M. (Org.). Como elaborar trabalhos monográficos em contabilidade: teoria e prática. São Paulo: Atlas, 2003.

CALIXTO, L. Contabilidade Ambiental: aplicação do ISAR em empresas do setor de mineração. Rio de Janeiro, 2004. Dissertação (Mestrado em Ciências Contábeis), Faculdade de Administração e Finanças, Universidade do Estado do Rio de Janeiro.

CAVALCANTI, C. Desenvolvimento e natureza: estudos para a sociedade sustentável. 2. ed. São Paulo: Cortez, 1998.

CONAMA. Resolução no 307 do CONAMA de 05/07/2002. Disponível em: <http://www. $\mathrm{mma}$.gov.br/port/conama/legiabre.cfm?codlegi=307>. Acesso em: 24/07/2012.

CUNHA, D. R.; PORTE, M. S.; NAHUZ JÚNIOR, J. S. Pesquisa cientifica em contabilidade ambiental: análise dos trabalhos publicados em periódicos nacionais de 2005 a 2010. Disponível em: <http://csearsouthamerica.org/2011/sites/default/files/ ca_020_publicacoes_2005_2010.pdf >. Acesso em: 24/07/2012.

FACHIN, O. Fundamentos de Metodologia. 3.ed. São Paulo: Saraiva, 2001.

FREZATTI, F; BORBA, J. Análise dos traços de tendência de uma amostra das revistas científicas da área de contabilidade publicadas em língua inglesa. Caderno de Estudos Fipecafi, v. 13, n. 25, p. 50-78, 2000.

GALLON, A.; SOUZA, F. C.; ROVER, S.; VAN BELLEN, H. M. Um estudo longitudinal da produção científica em administração direcionada à temática ambiental. Alcance (UNIVALI), v. 15, p. 81-101, 2008.

GIL, A. C. Como elaborar projetos de pesquisa. 4.ed. São Paulo: Atlas, 2002. 175 p.

JABBOUR, C. J. C.; SANTOS, F. C. A.; BARBIERI, J. C.. Gestão Ambiental Empresarial: um Levantamento da Produção Científica Brasileira Divulgada em Periódicos da Área de Administração entre 1996 e 2005. RAC, v. 12, n. 3, p. 689-715, Jul./Set. 2008.

INGWERSEN, P. The calculation of Web impact factors. Journal of Documentation, v. 54, n. 2, 1998, p. 236-243.

KANASHIRO, V. Produção acadêmica brasileira sobre sustentabilidade: análise da base Scielo Brasil. Disponível em: <www.anppas.org.br/encontro5/.../GT10-56-5220100903195607.pdf>. Acesso em: 25/08/2012.

LEFF, E. Discursos sustentáveis. São Paulo. Cortez Editora, 2010.

LORENZETTI, L.; DELIZOICOV, D. Temática ambiental: Um olhar sobre a produção acadêmica. In: ENCONTRO NACIONAL DE PESQUISA E EDUCAÇÃO EM CIÊNCIAS, 5., 2005, Bauru. Anais... Bauru, SP. 
MACHADO JÚNIOR, C.; SOUZA; M. T.; RIBEIRO; H. C.. A contribuição dos 15 anos do SIMPOI ao estudo da sustentabilidade ambiental: um estudo bibliométrico. In: SIMPÓSIO DE ADMINISTRAÇÃO DA PRODUÇÃO, LOGÍSTICA E OPERAÇÕES INTERNACIONAIS, 15., 2012, São Paulo. Anais... São Paulo, 2012.

MAIMON, D. Passaporte verde: gestão ambiental e competitividade. Rio de Janeiro: [s.n.], 1996.

MANSINHO, M. I.; SCHMIDT, L.. A emergência do ambiente nas ciências sociais: análise de um inventário bibliográfico. Análise Social, v. 29, p. 125-126, 1994.

MARTINEZ-ALIER, J. Da economia ecológica ao ecologismo popular. Blumenau. Ed. da FURB, 1998.

MERICO, L. F. K. (1996). Introdução à economia ecológica. Blumenau, Ed. da FURB.

MONTEIRO, C. A. Política de divulgação da Revista de Saúde Pública no meio científico internacional. [Editorial]. Revista Saúde Pública, v. 18, n. 5, out., São Paulo, 1984. Disponível em: <http://www.scielo.br/scielo.php?script=sci_ arttext\&pid=S0034-89101984000500001>. Acesso em: 06/09/2012.

MORETTI, S. L. A.; CAMPANARIO, M. A. A Produção Intelectual Brasileira em Responsabilidade Social Empresarial - RSE sob a Ótica da Bibliometria. RAC, v. 13, Edição Especial, art. 5, p. 68-86, 2009.

MURCIA, F. D. R.; SANTOS, A.; SALLOTI, B.; NASCIMENTO, A. Mapeamento da Pesquisa sobre Disclosure Ambiental no Cenário Internacional: Uma Revisão dos Artigos Publicados em Periódicos de Língua Inglesa no Período de 1997-2007. In: CONGRESSO USP DE CONTROLADORIA E CONTABILIDADE, 8., São Paulo. Anais... São Paulo, 2008.

MURCIA, F. D.; E BORBA, J. A. Possibilidade de inserção da pesquisa contábil brasileira no cenário internacional: Uma proposta de avaliação dos periódicos científicos de contabilidade e auditoria publicados em língua inglesa e disponibilizados no portal de periódicos da CAPES. Revista Contabilidade e Finanças, USP, v. 19, n. 46, p. $30-43,2008$.

NASCIMENTO, A. R.; SANTOS, A.; SALOTTI, B. M.; MURCIA, F. D. Disclosure social e ambiental: análise das pesquisas científicas veiculadas em periódicos de língua inglesa. Contabilidade Vista \& Revista, v. 20, p. 15-40, 2009.

NOVAIS, A. L. M.; JOÃO, B. N.; SERRALVO, F. A. Sustainability as a topic in business and management research: A bibliometric analysis. African Journal of Business Management, v. 6, n. 22, p. 6587-6596, 2012.

OLIVEIRA, M. C. Análise dos Periódicos Brasileiros de Contabilidade. Revista Contabilidade e Finanças - USP, São Paulo, n. 29, p. 68 - 86, maio/ago. 2002. Disponível em: <http://www.scielo.br/scielo.php?pid=S1519-70772002000200005\&script=sci_ arttext>. Acesso em: 22/07/2012.

REY, L. Como redigir trabalhos cientificos. Edgard Blücher: São Paulo, 1978. 
RUMMLER, G.; SILVA, V. R. Longevidade e dispersão física de periódicos nacionais sobre pesquisa, ensino e educação. Educação Temática Digital, v. 6, n. 2, p. 1-13, 2005. SANTOS, M. Técnica, espaço e tempo. Globalização e meio técnico-científicoinformacional. São Paulo: Hucitec, 1994.

SANTOS, M. A questão do meio ambiente: Desafios para a construção de uma perspectiva transdisciplinar. INTERFACEHS - Revista de Gestão Integrada em Saúde do Trabalho e Meio Ambiente, v.1, n.1, Trad 1, 2006. Disponível em: <http://www.interfacehs. sp.senac $. \mathrm{br} / \mathrm{br} /$ traducoes.asp? ed=1\&cod_artigo $=12>$. Acesso em 23/07/2012.

SEHNEM, S.; OLIVEIRA, M. A. S.; FERREIRA, E.; ROSSETO, A. M. Gestão e estratégia ambiental: um estudo bibliométrico sobre o interesse do tema nos periódicos acadêmicos brasileiros. REAd - Revista Eletrônica de Administração, v. 18, n. 2, 2012.

SILVA, B. G. Contabilidade ambiental. Curitiba: Juruá, 2008.

SILVA, M. Z.; DANI, A. C.; BEUREN, I. M.; KLOEPPEL, N. R. Características bibliométricas e sociométricas e de publicações da área ambiental em congressos e periódicos nacionais. In: ENCONTRO NACIONAL SOBRE GESTÃO EMPRESARIAL E MEIO AMBIENTE (ENGEMA), 13., São Paulo. Anais... São Paulo: USP, 2011.

SOUZA, M. T. S.; RIBEIRO, H. C. M.; MACHADO JÚNIOR, C.; CORRÊA, R.. Perfil e Evolução da Pesquisa em Sustentabilidade Ambiental: uma Análise Bibliométrica. In: ENCONTRO DA ASSOCIAÇÃO NACIONAL DE PÓS-GRADUAÇÃO EM ADMINISTRAÇÃO , 35., 2011, Rio de Janeiro. Anais... Rio de Janeiro: ANPAD, 2011.

TAUCHEN, J.; BRANDLI, L. L. A gestão ambiental em instituições de ensino superior: modelo para implantação em campus universitário. Gestão \& Produção, v. 13, n. 3, 2006.

WCED. Our common Future. Oxford: Oxford University Press, 1987.

VANTI, N. A. P. Da bibliometria à webometria: uma exploração conceitual dos mecanismos utilizados para medir o registro da informação e a difusão do conhecimento. Disponível em: <http://www.scielo.br/scielo.php?script=sci_ arttext\&pid=s0100-19652002000200016\&lng $=$ pt\&nrm=iso\&userID=-2>. Acesso em 06/09/2012. 


\section{DADOS DOS AUTORES}

\section{DENIZE DEMARCHE MINATTI FERREIRA^dminatti@terra.com.br} Doutora em Engenharia e Gestão do Conhecimento pela UFSC

Instituição de vinculação: Universidade Federal de Santa Catarina

Florianópolis/SC - Brasil

Áreas de interesse em pesquisa: Gestão Ambiental, Responsabilidade Socioambiental e Contabilidade Ambiental.

* Universidade Federal de Santa Catarina

Campus Universitário Reitor João David Ferreira Lima

Trindade Florianópolis/SC 88040-970

\section{CAROLINA AGUIAR DA ROSA carolaguiarrosa@gmail.com}

Graduada em Ciências Contábeis pela UFSC

Instituição de vinculação: Universidade Federal de Santa Catarina

Florianópolis/SC - Brasil

Áreas de interesse em pesquisa: Contabilidade Financeira, Ensino e Pesquisa em

Contabilidade e Contabilidade Ambiental.

\section{JOSÉ ALONSO BORBA jalonso@cse.ufsc.br}

Pós-Doutorado em Ciências Contábeis pela École des Hautes Études Commerciales de Montréal

Instituição de vinculação: Universidade Federal de Santa Catarina

Florianópolis/SC - Brasil

Áreas de interesse em pesquisa: Contabilidade Financeira, Ensino e Pesquisa em

Contabilidade e Administração e Finanças. 